Lisette M. Wiltink, Remi A. Nout, Marta Fiocco, Elma Meershoek-Klein Kranenbarg, Cornelis J.H. van de Velde, Carien L. Creutzberg, and Corrie A.M. Marijnen, Leiden University Medical Center Leiden; Ina M. Jürgenliemk-Schulz, University Medical Center Utrecht, Utrecht; Jan J. Jobsen, Medisch Spectum Twente, Enschede; Iris D. Nagtegaal, Radboud University Medical Center, Nijmegen; and Harm J.T. Rutten, Catharina Hospital Eindhoven, Eindhoven, the Netherlands.

Published online ahead of print at www.jco.org on December 22, 2014

Processed as a Rapid Communication manuscript.

Supported by Research Grant Nos. CKVO 90-01, CKVO 95-04, and CKTO 2001-04 from the Dutch Cancer Society and No. OWG 97/026 from the Dutch National Health Council.

Presented at the 56th Annual Meeting of the American Society for Radiation Oncology, San Francisco, CA, September 14-17, 2014.

Authors' disclosures of potential conflicts of interest are found in the article online at www.jco.org. Author contributions are found at the end of this article.

Corresponding author: Corrie A.M Marijnen, MD, PhD, Department of Clinical Oncology, K1-P, Leiden University Medical Center, PO Box 9600, 2300 RC Leiden, the Netherlands: e-mail: marijnen@lumc.nl.

C 2014 by American Society of Clinical Oncology

0732-183X/15/3315w-1640w/\$20.00 DOI: 10.1200/JCO.2014.58.6693

\title{
No Increased Risk of Second Cancer After Radiotherapy in Patients Treated for Rectal or Endometrial Cancer in the Randomized TME, PORTEC-1, and PORTEC-2 Trials
}

Lisette M. Wiltink, Remi A. Nout, Marta Fiocco, Elma Meershoek-Klein Kranenbarg,

Ina M. Jürgenliemk-Schulz, Jan J. Jobsen, Iris D. Nagtegaal, Harm J.T. Rutten, Cornelis J.H. van de Velde, Carien L. Creutzberg, and Corrie A.M. Marijnen

Listen to the podcast by Dr Jang at www.jco.org/podcasts

$$
\begin{array}{llllllll}
\text { A } & \text { B } & \text { S } & \text { T } & \text { R } & \text { A } & \text { C } & \text { T }
\end{array}
$$

\section{Purpose}

This study investigated the long-term probability of developing a second cancer in a large pooled cohort of patients treated with surgery with or without radiotherapy (RT).

\section{Patients and Methods}

All second cancers diagnosed in patients included in the TME, PORTEC-1, and PORTEC-2 trials were analyzed. In the TME trial, patients with rectal cancer $(n=1,530)$ were randomly allocated to preoperative external-beam RT (EBRT; 25 Gy in five fractions) or no RT. In the PORTEC trials, patients with endometrial cancer were randomly assigned to postoperative EBRT (46 Gy in 2-Gy fractions) versus no RT (PORTEC-1; $\mathrm{n}=714$ ) or EBRT versus vaginal brachytherapy (VBT; PORTEC-2; $n=427)$.

\section{Results}

A total of 2,554 patients were analyzed (median follow-up, 13.0 years; range 1.8 to 21.2 years). No differences were found in second cancer probability between patients who were treated without RT (10- and 15-year rates, $15.8 \%$ and $26.5 \%$, respectively) and those treated with EBRT (10- and 15 -year rates, $15.4 \%$ and $25.6 \%$, respectively) or VBT (10-year rate, $14.9 \%$ ). In the individual trials, no significant differences were found between treatment arms. All cancer survivors had a higher risk of developing a second cancer compared with an age- and sex-matched general population. The standardized incidence ratio for any second cancer was $2.98(95 \% \mathrm{Cl}, 2.82$ to 3.14$)$.

\section{Conclusion}

In this pooled trial cohort of $>2,500$ patients with pelvic cancers, those who underwent EBRT or VBT had no higher probability of developing a second cancer than patients who were treated with surgery alone. However, patients with rectal or endometrial cancer had an increased probability of developing a second cancer compared with the general population.

\section{J Clin Oncol 33:1640-1646. (C) 2014 by American Society of Clinical Oncology}

\section{INTRODUCTION}

Cancer survivors are at increased risk of developing a second cancer compared with the general population. ${ }^{1}$ This increased risk has been explained by several factors, such as lifestyle factors, genetic susceptibility, and administered chemotherapy or radiotherapy (RT). In a large US SEER-based study, RT was found to be related to a relatively small proportion $(8 \%)$ of second cancers; most second cancers were related to other factors. ${ }^{2}$ Increased risk for an RT-related second cancer was found with increasing time since treatment and with decreasing age at diagnosis.
During the last decades, the role of (neo) adjuvant RT for rectal and endometrial cancers has been investigated in several large trials. For both rectal and endometrial cancers, external-beam RT (EBRT) increased locoregional control, but this did not translate into an improvement in overall survival. ${ }^{3-6}$ The benefit of EBRT for local control should therefore be balanced against the risk of adverse effects, such as long-lasting treatment-related bowel symptoms and RT-related second cancers. Several large studies have assessed the risk of a second cancer in patients treated with RT after surgery for rectal or endometrial cancer, with varying results. ${ }^{7-10} \mathrm{Al}$ though some studies have found an increased risk of 
developing a second cancer after $\mathrm{RT}^{7}$ especially in patients treated at younger ages, ${ }^{8}$ others have reported that RT did not lead to overall differences in second cancer risk. ${ }^{9,10}$

The PORTEC-1 (Post Operative Radiation Therapy in Endometrial Carcinoma 1) and PORTEC-2 and TME (Total Mesorectal Excision) trials have had a major impact on guidelines for (neo) adjuvant RT for endometrial and rectal cancers, respectively. These three randomized trials together included $>2,500$ patients, with long and complete follow-up information for patients with rectal or endometrial cancer who received EBRT or vaginal brachytherapy (VBT) to the pelvic region, compared with patients treated without RT. ${ }^{3,4,11}$ The databases from these large randomized trials were combined to evaluate the long-term probability of developing a second cancer after the primary rectal or endometrial cancer in patients treated with or without pelvic RT.

\section{PATIENTS AND METHODS}

\section{Patients and Treatment}

In the multicenter TME trial, 1,530 Dutch rectal patients were randomly assigned to preoperative EBRT followed by standardized total mesorectal excision (TME) surgery or TME alone between January 1996 and December 1999. Details of the study design have been described previously., ${ }^{42}$ Eligible patients had a clinically resectable adenocarcinoma, without evidence of distant metastases, and with an inferior tumor margin below the level of S1/S2 and within $15 \mathrm{~cm}$ from the anal verge. Patients allocated to EBRT were treated with a total dose of $25 \mathrm{~Gy}$ in five fractions delivered over 5 to 7 days by a threeor four-field technique. ${ }^{4,12}$

In the multicenter PORTEC-1 trial, 715 patients with endometrial adenocarcinoma were enrolled between June 1990 and December 1997. Details of the PORTEC-1 trial have been reported elsewhere. ${ }^{3,13}$ All patients underwent total extrafascial hysterectomy with bilateral salphingo-oophorectomy without lymphadenectomy and were randomly assigned to postoperative EBRT or no additional treatment (no RT). Eligible patients had postoperative stage I (according to International Federation of Gynecology and Obstetrics 1988 staging system) endometrial adenocarcinoma and either grade 1 disease with deep $(\geq 50 \%)$ myometrial invasion, grade 2 disease with any invasion, or grade 3 with superficial $(<$ $50 \%$ ) invasion. Patients allocated to EBRT were treated with a total dose of $46 \mathrm{~Gy}$ in 23 fractions delivered by an anterioposterior opposed-field (30\%) or three- or four-field technique (70\%)., ${ }^{3,13}$ The EBRT treatment volume and anatomic region were similar for endometrial and rectal cancers.

In the multicenter PORTEC-2 trial, 427 patients with endometrial cancer were enrolled between May 2002 and September 2006. Details of the PORTEC-2 trial have been reported in previous publications. ${ }^{11,14}$ All patients underwent total extrafascial hysterectomy with bilateral salphingooophorectomy and were randomly allocated to postoperative EBRT or VBT. Eligible patients had stage I (according to International Federation of Gynecology and Obstetrics 1988 staging system) endometrial carcinoma with high or intermediate risk factors (ie, age $\geq 60$ years, with either $\geq 50 \%$ myometrial invasion and grade 1 or 2 disease or $<50 \%$ invasion and grade 3 disease), or any age with stage IIA disease (except grade 3 disease with $>50 \%$ myometrial invasion). Patients assigned to EBRT were treated with a dose of $46 \mathrm{~Gy}$ in 23 fractions. Computerized treatment planning was used with a threedimensional conformal or multiple-field technique, with individual shielding in all fields. For patients assigned to VBT, the upper half of the vagina was treated using a vaginal cylinder. Brachytherapy schedules were as follows: high-dose rate, 21 Gy at 5-mm depth in three fractions of 7 Gy over 2 weeks (87\%); low-dose rate, $30 \mathrm{~Gy}(9 \%)$; or medium-dose rate, 28 Gy at 5-mm depth in one session $(4 \%) .{ }^{11}$

An ethics committee approved the design of each trial, and all patients provided informed consent. Because patients in the TME and PORTEC-1 trials were no longer undergoing active follow-up in 2013, the Dutch Pathology Registry of the nationwide network and registry of histopathology and cytopathology in the Netherlands (PALGA) was used to verify the occurrence of second cancers. ${ }^{15}$ When inconsistencies in second cancers were found between data provided by PALGA and the trial database, patients' general practitioners and/or treating hospitals were contacted. Because patients in the PORTEC-2 trial were still undergoing active follow-up in 2013, second cancer incidence in these patients was collected from the trial database. In the Netherlands (and at PALGA), the guidelines for the definition of multiple primaries (ie, second cancers) proposed by the International Association of Cancer Registries and International Agency for Research on Cancer are followed. ${ }^{16}$

\section{Statistical Methods}

All data were analyzed by treatment actually received by patients. In the TME trial, 82 (11.4\%) of 718 patients assigned to no preoperative RT received (mainly postoperative) EBRT in case of R1 resection, and all 695 patients assigned to EBRT received EBRT. In the PORTEC-1 trial, six (1.7\%) of 360 patients assigned to no RT received EBRT, and 15 (4.2\%) of 354 patients assigned to EBRT did not receive EBRT. In the PORTEC-2 trial, three (1.4\%) and one $(0.5 \%)$ of 213 patients assigned to VBT received no RT and EBRT, respectively; five $(2.3 \%)$ and one $(0.5 \%)$ of 214 patients assigned to EBRT received VBT and no RT, respectively. Median follow-up time was assessed by employing reverse Kaplan-Meier methodology. ${ }^{17}$ A competing-risk model with death as a competing event was used to estimate the cumulative incidence (ie, probability) of developing a second primary cancer in the different treatment arms. ${ }^{18}$ Gray's test was used to assess the statistical difference between the estimated cumulative incidence of second cancers. ${ }^{19}$ Time at risk started at random assignment date and ended at date of occurrence of the first second cancer, death, or last date of study follow-up, whichever occurred first. For subgroups, time at risk ended at date of occurrence of the first second cancer of a specific type, death, or last date of study follow-up. To take the background incidence of cancers in account, data on the Dutch general population provided by the Netherlands Cancer Registry were used. ${ }^{20}$ To compare the number of second cancers in the cohort under study with the number of cancers in the Dutch population, standardized incidence ratios (SIRs) were estimated. A Poisson regression model was employed to estimate SIRs and confidence intervals. SIRs were estimated as the ratios of the observed patients' occurrence of first second cancers with the expected occurrence in the Dutch general population, stratified by age, sex, and calendar time. Because basal cell carcinomas are not registered by the Netherlands Cancer Registry, observed basal cell carcinomas in the trials were excluded from the comparison with the general population. Absolute excess risks were calculated as the observed patients' occurrence of second cancers minus the number of expected cancers, divided by person-years at risk and multiplied by 10.000 . A two-sided $P$ value less than .05 was considered statistically significant. Analyses were performed using IBM SPSS Statistics (version 20.0; SPSS, Chicago, IL). Estimation of SIRs was computed in R (version R-2.15.3; http://www.r-project.org). The Mstate library in $\mathrm{R}$ was used for competing-risk analyses. ${ }^{21,22}$

\section{RESULTS}

A total of 2,554 patients from the TME $(\mathrm{n}=1413)$, PORTEC-1 $(\mathrm{n}=$ 714), and PORTEC-2 $(\mathrm{n}=427)$ trials were analyzed (Fig 1). Overall median follow-up time was 13.0 years (range, 1.8 to 21.2 years): 14.0 years (range, 2.0 to 16.0 years) in the TME trial, 12.6 years (range, 2.8 to 21.2 years) in the PORTEC-1 trial, and 7.5 years (range, 1.8 to 10.5 years) in the PORTEC-2 trial. Table 1 summarizes patient and tumor characteristics. Baseline patient characteristics were equally balanced among the treatment arms in individual studies. ${ }^{3,4,11}$

In the pooled cohort of 2,554 patients, 759 cancers were diagnosed in 549 patients (21.5\%). In the TME trial, 306 patients $(21.7 \%)$ developed a second cancer, compared with 196 (27.5\%) in the PORTEC-1 trial and 47 (11.0\%) in the PORTEC-2 trial, reflecting the differences in follow-up among the trials. The most common cancers were basal cell carcinomas of the skin $(n=268)$, followed by breast 


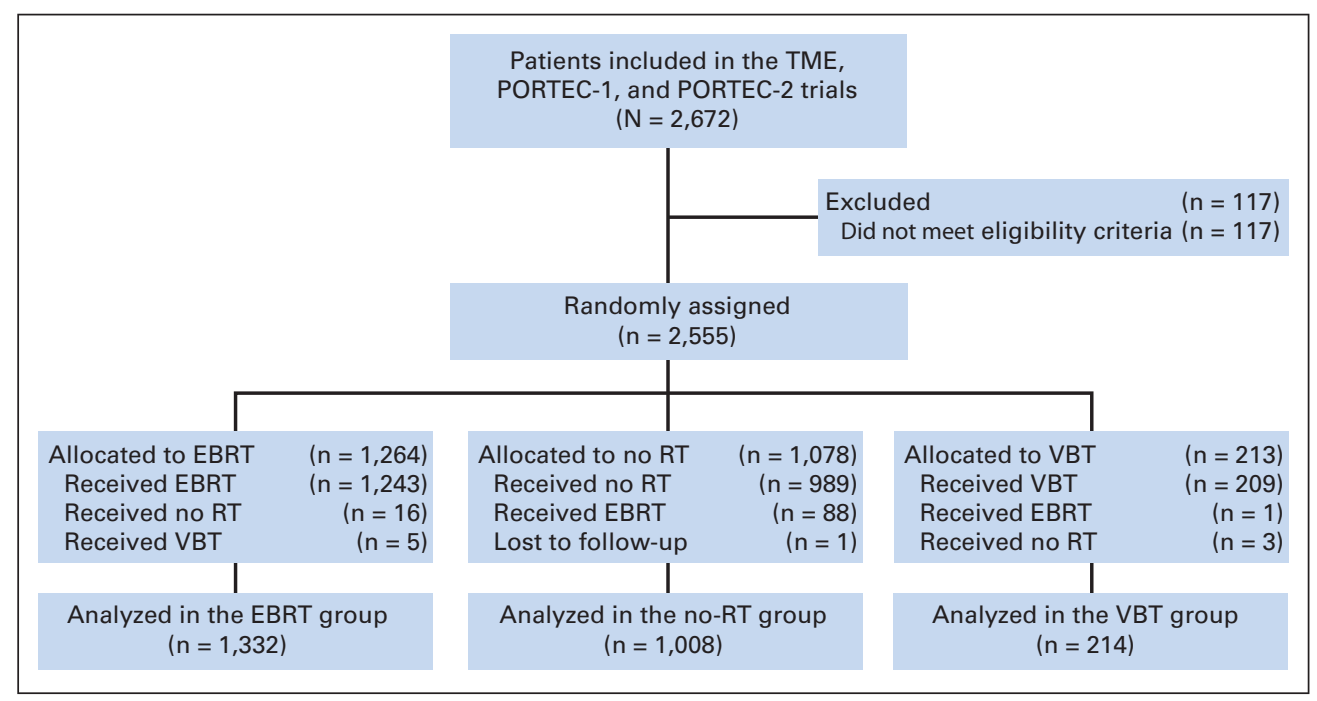

Fig 1. CONSORT diagram. EBRT, external-beam radiotherapy; PORTEC, Post Operative Radiation Therapy in Endometrial Carcinoma; RT, radiotherapy; TME, Total Mesorectal Excision; VBT, vaginal brachytherapy.

$(\mathrm{n}=75)$, lung $(\mathrm{n}=55)$, and colon cancers $(\mathrm{n}=52)$. The distribution of cancer types is listed in Table 2.

No difference in the probability of developing a second cancer was found between the treatment arms (10-year rates: no RT, 15.8\%; EBRT, 15.4\%; VBT, 14.9\%; 15-year rates: no RT, 26.5\%; EBRT, $25.6 \% ; P=.94$; Fig 2A). Similarly, in the individual trials, no differences were found between treatment arms regarding 10-year rates (TME trial: no RT, 15.3\% v EBRT, 14.8\% [Fig 2B]; PORTEC-1 trial: no RT, $16.9 \% v$ EBRT, $17.3 \%$ [Fig 2C]; PORTEC-2 trial: VBT, $14.9 \%$ $v$ EBRT, $14.4 \%$ [Fig 2D]). Similarly, after exclusion of basal cell carci- nomas of the skin from the analysis, no statistical significant differences were found. When pooled treatment groups of all studies together were compared, no differences were seen in cumulative incidence of development of a second cancer at a specific site, except for rectosigmoid cancer. However, when excluding the TME patients, there was no statistical difference in rectosigmoid cancer incidence between the treatment arms (10-year rates: VBT, 1.6\%; no RT, $0.84 \%$; EBRT, $0.54 \%$; $P=.10)$. Specifically, patients who underwent EBRT did not have more second cancers in the abdominal or pelvic area than nonirradiated patients (data not shown).

\begin{tabular}{|c|c|c|c|c|c|c|c|c|}
\hline \multicolumn{9}{|l|}{ Age, years } \\
\hline Median & \multicolumn{2}{|c|}{66} & \multicolumn{2}{|c|}{65} & \multicolumn{2}{|c|}{66} & \multicolumn{2}{|c|}{69} \\
\hline Range & \multicolumn{2}{|c|}{ 23-92 } & \multicolumn{2}{|c|}{$23-92$} & \multicolumn{2}{|c|}{$41-90$} & \multicolumn{2}{|c|}{$49-89$} \\
\hline \multicolumn{9}{|l|}{ Sex } \\
\hline Male & 909 & 35.6 & 909 & 64.3 & - & - & - & - \\
\hline Female & 1,645 & 64.4 & 504 & 35.7 & 714 & 100 & 427 & 100 \\
\hline \multicolumn{9}{|l|}{ Treatment } \\
\hline No RT & 1,008 & 39.4 & 635 & 44.9 & 369 & 51.6 & 4 & 0.9 \\
\hline EBRT & 1,332 & 52.2 & 778 & 55.1 & 345 & 48.3 & 209 & 48.9 \\
\hline ॥ & 381 & 27 & 381 & 27 & - & - & - & - \\
\hline III & 506 & 35.8 & 506 & 35.8 & - & - & - & - \\
\hline IV & 81 & 5.7 & 81 & 5.7 & - & - & - & - \\
\hline \multicolumn{9}{|l|}{ FIGO 1998 stage } \\
\hline IB & 329 & 28.8 & - & - & 294 & 41.2 & 35 & 8.2 \\
\hline IC & 763 & 66.8 & - & - & 420 & 58.8 & 343 & 80.3 \\
\hline IIA & 49 & 4.3 & - & - & - & - & 49 & 11.5 \\
\hline
\end{tabular}




\begin{tabular}{|c|c|c|c|c|c|c|c|c|c|c|c|c|c|c|c|c|c|c|c|c|}
\hline \multirow[b]{3}{*}{ Cancer Type } & \multicolumn{6}{|c|}{ All Trials } & \multicolumn{4}{|c|}{ TME Trial } & \multicolumn{4}{|c|}{ PORTEC-1 Trial } & \multicolumn{6}{|c|}{ PORTEC-2 Trial } \\
\hline & \multicolumn{2}{|c|}{$\begin{array}{c}\begin{array}{c}\text { EBRT } \\
(n=1,332)\end{array} \\
\end{array}$} & \multicolumn{2}{|c|}{$\begin{array}{c}\text { No RT } \\
(\mathrm{n}=1,008)\end{array}$} & \multicolumn{2}{|c|}{$\begin{array}{c}\text { VBT } \\
(n=214)\end{array}$} & \multicolumn{2}{|c|}{$\begin{array}{c}\text { EBRT } \\
(n=778)\end{array}$} & \multicolumn{2}{|c|}{$\begin{array}{c}\text { No RT } \\
(n=635)\end{array}$} & \multicolumn{2}{|c|}{$\begin{array}{c}\text { EBRT } \\
(\mathrm{n}=345)\end{array}$} & \multicolumn{2}{|c|}{$\begin{array}{c}\text { No RT } \\
(n=369)\end{array}$} & \multicolumn{2}{|c|}{$\begin{array}{c}\text { EBRT } \\
(n=209)\end{array}$} & \multicolumn{2}{|c|}{$\begin{array}{l}\text { No RT } \\
(n=4)\end{array}$} & \multicolumn{2}{|c|}{$\begin{array}{c}\text { VBT } \\
(n=214)\end{array}$} \\
\hline & No. & $\%$ & No. & $\%$ & No. & $\%$ & No. & $\%$ & No. & $\%$ & No. & $\%$ & No. & $\%$ & No. & $\%$ & No. & $\%$ & No. & $\%$ \\
\hline Any & 394 & 100.0 & 336 & 100.0 & 29 & 100.0 & 251 & 100.0 & 205 & 100.0 & 121 & 100.0 & 130 & 100.0 & 22 & 100.0 & 1 & 100.0 & 29 & 100.0 \\
\hline Hematologic & 18 & 4.6 & 17 & 5.1 & 3 & 10.3 & 10 & 4.0 & 11 & 5.4 & 5 & 4.1 & 6 & 4.6 & 3 & 13.6 & 0 & 0 & 3 & 10.3 \\
\hline Skin & 178 & 45.2 & 154 & 45.8 & 6 & 20.7 & 136 & 54.2 & 95 & 46.3 & 39 & 32.2 & 59 & 45.4 & 3 & 13.6 & 0 & 0 & 6 & 20.7 \\
\hline Breast & 31 & 7.9 & 38 & 11.1 & 6 & 20.7 & 3 & 1.2 & 10 & 4.9 & 24 & 19.8 & 27 & 20.8 & 4 & 18.2 & 1 & 100 & 6 & 20.7 \\
\hline Respiratory & 34 & 8.6 & 21 & 6.2 & 3 & 10.3 & 22 & 8.8 & 15 & 7.3 & 9 & 7.4 & 6 & 4.6 & 3 & 13.6 & 0 & 0 & 3 & 10.3 \\
\hline $\mathrm{Gl}$ & 68 & 17.3 & 41 & 12.2 & 7 & 24.1 & 35 & 13.9 & 24 & 11.7 & 27 & 22.3 & 17 & 13.1 & 6 & 27.3 & 0 & 0 & 7 & 24.1 \\
\hline Colon & 30 & & 22 & & 0 & & 17 & & 14 & & 10 & & 8 & & 3 & & 0 & & 0 & \\
\hline Rectosigmoid & 3 & & 4 & & 5 & & 0 & & 0 & & 2 & & 4 & & 1 & & 0 & & 5 & \\
\hline Rectal & 6 & & 2 & & 1 & & 1 & & 1 & & 5 & & 1 & & 0 & & 0 & & 1 & \\
\hline Other & 29 & & 13 & & 1 & & 17 & & 9 & & 10 & & 4 & & 2 & & 0 & & 1 & \\
\hline Urogenital & 50 & 12.7 & 45 & 13.4 & 2 & 6.9 & 35 & 13.9 & 41 & 20.0 & 13 & 10.7 & 4 & 3.1 & 2 & 9.1 & 0 & 0 & 2 & 6.9 \\
\hline $\begin{array}{l}\text { Urinary } \\
\text { bladder }\end{array}$ & 19 & & 16 & & 1 & & 10 & & 14 & & 8 & & 2 & & 1 & & 0 & 0 & 1 & \\
\hline Prostate & 16 & & 16 & & 0 & & 16 & & 16 & & - & & - & & - & & - & & - & \\
\hline Corpus uteri & 3 & & 4 & & 0 & & 3 & & 4 & & 0 & & 0 & & 0 & & 0 & & 0 & \\
\hline Ovarian & 2 & & 1 & & 0 & & 1 & & 1 & & 1 & & 0 & & 0 & & 0 & & 0 & \\
\hline Other & 10 & & 8 & & 1 & & 5 & & 6 & & 4 & & 2 & & 1 & & 0 & & 1 & \\
\hline Other & 15 & 3.8 & 20 & 6.0 & 2 & 6.9 & 10 & 4.0 & 9 & 4.4 & 4 & 3.3 & 11 & 8.5 & 1 & 4.5 & 0 & 0 & 2 & 6.9 \\
\hline
\end{tabular}

\section{Age and Sex}

Although patients age $\leq 60$ years at diagnosis of primary cancer in general had a higher second cancer probability than those age $>60$ years (15-year rates: $27.2 \% v 23.9 \%$, respectively; $P=.01$ ), there was no difference in second cancer probability between treatment arms for patients age $\leq 60$ years, nor between treatment arms for patients age $>60$ years. In addition, no differences in cumulative probability of a second cancer were found between treatment groups in men or women alone (data not shown).

\section{Comparison With General Population}

SIR based on all included patients for all types of second cancers was 2.98 (95\% CI, 2.82 to 3.14), which results in 154 excess cases per 10.000 patients per year, as compared with a matched general population. SIR based on all patients age $\leq 60$ years at diagnosis was 5.47 (95\% CI, 4.73 to 6.31 ), and SIR based on all patients age $>60$ years was 2.76 (95\% CI, 2.60 to 2.93 ). All SIR and absolute excess risk values are listed in Table 3.

\section{DISCUSSION}

In this pooled analysis of $>2,500$ patients with pelvic cancers treated in three large randomized trials, the probability of developing a second cancer was not different between patients treated with or without RT. However, patients treated for rectal or endometrial cancer had a higher probability of developing a second cancer compared with the general population, stratified by age, sex, and calendar time.

Strengths of this pooled analysis of the TME, PORTEC-1, and PORTEC-2 trials are the large group of patients with pelvic cancers ( $N$ $=2,554$ ) and the random treatment allocation, ensuring that trial groups were comparable with regard to lifestyle factors, genetic sus- ceptibility, age, and other prognostic factors. Follow-up information of trial patients was complete, and second tumors were verified using the Dutch Pathology Registry.

A possible limitation of the study is the difference in total EBRT dose. The biologic effective dose using $\alpha / \beta 3$ was $46 \mathrm{~Gy}$ in the PORTEC trials, compared with $40 \mathrm{~Gy}$ in the TME trial. No differences were found in development of a second cancer at a specific site or in development of sarcomas. Because the rectum was removed in TME patients, an analysis was performed in which TME patients were excluded. This analysis showed no statistical difference between treatment arms for rectosigmoid cancer, probably because of the smaller sample size. Furthermore, a relatively small number of patients (29\%) were age $\leq 60$ years at random assignment. In the Dutch population, the incidence of cancer is highest in those between ages 60 and 80 years, ${ }^{20}$ which is reflected in this pooled cohort, with the majority of patients age $>60$ years $(71 \%)$, making it a representative cohort for this analysis.

The occurrence of a second cancer has also been analyzed in other randomized trials. ${ }^{7,8}$ Patients with rectal cancer in the Uppsala trial and Swedish rectal cancer trial were treated with pre- or postoperative EBRT or surgery alone. In these trials, more second cancers developed in the EBRT group (stratified relative risk [RR], 1.85; 95\% CI, 1.23 to 2.78 ), and an increased risk of a second cancer was found in the irradiated group for organs in or near the irradiated volume (stratified RR, 2.04; 95\% CI, 1.10 to 3.79). Actuarial life-table procedures were used to calculate the cumulative proportion of second cancers. ${ }^{7}$ In another randomized controlled trial, 568 patients with stage I endometrial cancer were randomly allocated to VBT followed by EBRT or VBT alone. An increased risk of a second cancer was found after EBRT (hazard ratio [HR], 1.42; 95\% CI, 1.01 to 2.00), and an even higher risk was found in women treated with EBRT who were age $<60$ years at 


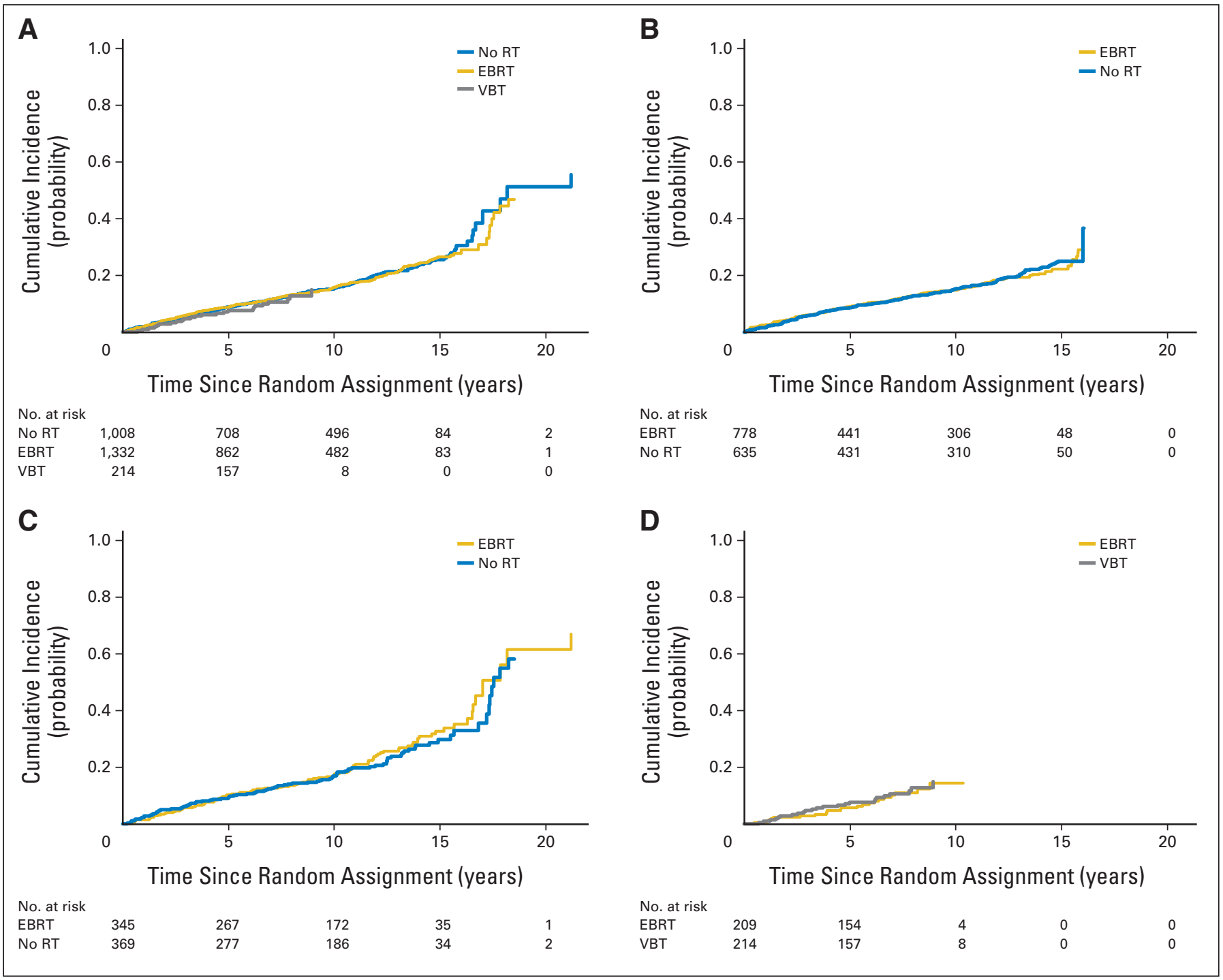

Fig 2. Cumulative probability of developing second cancer in (A) all, (B) TME (Total Mesorectal Excision), (C) PORTEC-1 (Post Operative Radiation Therapy in Endometrial Carcinoma 1), and (D) PORTEC-2 trials. NOTE. Because only four patients were included in no-RT group in the PORTEC-2 trial, these patients are not represented in panel D. EBRT, external-beam radiotherapy; RT, radiotherapy; VBT, vaginal brachytherapy.

diagnosis (HR, 2.02; 95\% CI, 1.30 to 3.15$).^{8}$ In this analysis, in which actuarial life-table procedures were also used, death was not taken into account as a competing event. Therefore, the probability of developing a second cancer was overestimated because of the number of patients who died before experiencing a second cancer. ${ }^{23}$ Other nonrandom-

\begin{tabular}{|lcccccc|}
\hline \multicolumn{7}{|c|}{ Table 3. SIRs for All Types of Second Cancer* } \\
\hline Characteristic & Observed & Expected & SIR & $95 \%$ CI & AER \\
\hline All patients & 449 & 151 & 2.98 & 2.82 to 3.14 & 154 \\
Male sex & 167 & 52 & 3.23 & 2.98 to 3.50 & 178 \\
Female sex & 282 & 101 & 2.78 & 2.58 to 3.00 & 140 \\
Age $\leq 60$ years & 121 & 22 & 5.47 & 4.73 to 6.31 & 151 \\
Age $>60$ years & 328 & 119 & 2.76 & 2.60 to 2.93 & 163 \\
\hline Abbreviations: AER, absolute excess risk; SIR, standardized incidence ratio. \\
*Excluding basal cell carcinomas. \\
tPer 10,000 persons per year.
\end{tabular}

ized studies have used competing-risk models to analyze the incidence of second cancers. In a retrospective cohort study, data from 69,739 patients with endometrial cancer from the US SEER cancer registries were used. Patients treated with EBRT developed more second cancers compared with patients treated without RT $(P<.001)$, especially colon $(P<.001)$, rectal $(P=.017)$, bladder $(P<.001)$, vaginal $(P<$ $.04)$, and soft tissue cancers $(P=.014)$. Patients receiving VBT only showed an increased risk for a second cancer of the urinary bladder $(P=.006) .{ }^{10}$ Another large SEER study evaluated the association between RT and second cancers in 90,502 patients with endometrial cancer. The RR for developing a second cancer after RT was 1.25 (95\% CI, 1.20 to 1.29), and an increased risk of developing a second cancer was found in the radiation field and after a longer latency period $(>10$ years). ${ }^{24}$ In contrast, a different study, which used the US SEER registries to evaluate the association between RT and second cancers in patients with primary rectal cancer, did not find a significant difference between irradiated $(\mathrm{n}=5,641)$ and nonirradiated patients $(\mathrm{n}=$ 
$15,269 ; \mathrm{HR}, 1.02 ; 95 \% \mathrm{CI}, 0.92$ to 1.12$)$. Irradiated patients seemed to have a significantly decreased rate of second cancers of the prostate and breast, whereas the rates for cancers of the urinary bladder, uterine corpus, and cervix were increased. ${ }^{9}$ Finally, a SEER registry-based study of 647,672 patients with different primary cancers found an increased RR of developing a second cancer after treatment with RT. RRs were highest for organs that received $>5$ Gy and increased with longer follow-up time and younger age at diagnosis of the first primary cancer. However, it was estimated that only $8 \%$ of the second cancers in irradiated patients might have been related to RT, compared with other factors, such as lifestyle factors, genetic susceptibility, and chemotherapy. ${ }^{2}$

This finding of only a small proportion of second cancers being attributable to RT might explain why our randomly assigned EBRT and VBT groups did not develop significantly more second cancers than patients treated without RT. Furthermore, several studies we have cited found an increasing risk when follow-up time increased. Our follow-up time did not go beyond 20 years after diagnosis of the primary cancer. However, because the median age of our patients was 66 years at diagnosis, the clinical relevance of an even longer follow-up time is limited. Furthermore, in contrast to studies using the SEER registries, with selection and treatment biases, we investigated the incidence of second cancers in randomized controlled trials for which it could be safely assumed that all treatment groups were equal with regard to lifestyle factors and genetic susceptibility, which may not be the case in retrospective cohort studies.

SIRs found in our study suggest that these patients with rectal or endometrial cancer had a $3 \times$ higher probability of developing a second primary cancer, as could be expected based on the incidence of cancer in a sex- and age-matched general Dutch population. For patients age $\leq 60$ years at diagnosis, this probability even increased to $5.5 \times$. This higher risk of developing a second cancer is most likely caused by several etiologic factors, such as lifestyle, environment, and host factors and interactions and other influences (eg, geneenvironment and gene-gene interactions). ${ }^{25}$ Etiologic factors involved in the development of a primary cancer probably also contribute to the development of a second cancer. For instance, patients could be more susceptible to primary and secondary cancers because of inherited or acquired genetic factors, like mutations in mismatch repair genes, TP53, or the Wnt signaling pathway, or because of Lynch syndrome. However, both for rectal and endometrial cancers, it is estimated that only $1 \%$ to $5 \%$ of cancers in unselected patient groups are related to Lynch syndrome. Therefore, the impact of Lynch syndrome on the overall burden of second cancers in this cohort is limited. Furthermore, lifestyle factors may also contribute to the development of cancers (eg, increased body-mass index is associated with increased risk for rectal, endometrial, and several other cancers). ${ }^{26}$

In conclusion, in this large pooled cohort of $>2,500$ patients from randomized trials with a median follow-up of 13.0 years, no increased risk of developing a second cancer was found in patients who underwent pelvic EBRT, which is important for counseling and shared decision making. In addition, both patients and physicians should be aware during follow-up that rectal and endometrial cancer survivors have a $3 \times$ higher risk of developing a second primary cancer compared with the general population, with basal cell skin, breast, lung, and colon cancers being most common.

\section{AUTHORS' DISCLOSURES OF POTENTIAL CONFLICTS OF INTEREST}

Disclosures provided by the authors are available with this article at www.jco.org.

\section{AUTHOR CONTRIBUTIONS}

Conception and design: Lisette M. Wiltink, Remi A. Nout, Carien L. Creutzberg, Corrie A.M. Marijnen

Collection and assembly of data: Lisette M. Wiltink, Remi A. Nout, Elma Meershoek-Klein Kranenbarg, Ina M. Jürgenliemk-Schulz, Jan J. Jobsen, Iris D. Nagtegaal, Harm J.T. Rutten, Cornelis J.H. van de Velde, Carien L. Creutzberg, Corrie A.M. Marijnen

Data analysis and interpretation: Lisette M. Wiltink, Remi A. Nout, Marta Fiocco, Carien L. Creutzberg, Corrie A.M. Marijnen

Manuscript writing: All authors

Final approval of manuscript: All authors

\section{REFERENCES}

1. Liu L, de Vries E, Louwman M, et al: Prevalence of multiple malignancies in the Netherlands in 2007. Int J Cancer 128:1659-1667, 2011

2. Berrington de Gonzalez A, Curtis RE, Kry SF, et al: Proportion of second cancers attributable to radiotherapy treatment in adults: A cohort study in the US SEER cancer registries. Lancet Oncol 12:353-360, 2011

3. Creutzberg $C L$, van Putten WL, Koper PC, et al: Surgery and postoperative radiotherapy versus surgery alone for patients with stage- 1 endometrial carcinoma: Multicentre randomised trial-PORTEC Study Group: Post Operative Radiation Therapy in Endometrial Carcinoma. Lancet 355:1404-1411, 2000

4. Kapiteijn E, Marijnen CA, Nagtegaal ID, et al: Preoperative radiotherapy combined with total mesorectal excision for resectable rectal cancer. N Engl J Med 345:638-646, 2001

5. Blake P, Swart AM, Orton J, et al: Adjuvant external beam radiotherapy in the treatment of endometrial cancer (MRC ASTEC and NCIC CTG EN. 5 randomised trials): Pooled trial results, systematic review, and meta-analysis. Lancet 373:137-146, 2009
6. Sauer R, Liersch T, Merkel S, et al: Preoperative versus postoperative chemoradiotherapy for locally advanced rectal cancer: Results of the German CAO/ARO/AIO-94 randomized phase III trial after a median follow-up of 11 years. J Clin Oncol 30:1926-1933, 2012

7. Birgisson $H$, Påhlman L, Gunnarsson $U$, et al: Occurrence of second cancers in patients treated with radiotherapy for rectal cancer. J Clin Oncol 23:6126-6131, 2005

8. Onsrud M, Cvancarova M, Hellebust TP, et al: Long-term outcomes after pelvic radiation for earlystage endometrial cancer. J Clin Oncol 31:39513956, 2013

9. Kendal WS, Nicholas G: A population-based analysis of second primary cancers after irradiation for rectal cancer. Am J Clin Oncol 30:333-339, 2007

10. Brown AP, Neeley ES, Werner $T$, et al: A population-based study of subsequent primary malignancies after endometrial cancer: Genetic, environmental, and treatment-related associations. Int J Radiat Oncol Biol Phys 78:127-135, 2010

11. Nout RA, Smit VT, Putter $H$, et al: Vaginal brachytherapy versus pelvic external beam radiotherapy for patients with endometrial cancer of high- intermediate risk (PORTEC-2): An open-label, noninferiority, randomised trial. Lancet 375:816-823, 2010

12. Marijnen CA, Kapiteijn E, van de Velde CJ, et al: Acute side effects and complications after shortterm preoperative radiotherapy combined with total mesorectal excision in primary rectal cancer: Report of a multicenter randomized trial. J Clin Oncol 20: 817-825, 2002

13. Creutzberg $C L$, van Putten $W L$, Koper $P C$, et al: The morbidity of treatment for patients with stage I endometrial cancer: Results from a randomized trial. Int J Radiat Oncol Biol Phys 51:1246-1255, 2001

14. Nout RA, Putter $H$, Jürgenliemk-Schulz IM, et al: Quality of life after pelvic radiotherapy or vaginal brachytherapy for endometrial cancer: First results of the randomized PORTEC-2 trial. J Clin Oncol 27:3547-3556, 2009

15. Casparie M, Tiebosch AT, Burger G, et al: Pathology databanking and biobanking in the Netherlands, a central role for PALGA, the nationwide histopathology and cytopathology data network and archive. Cell Oncol 29:19-24, 2007

16. International rules for multiple primary cancers (ICD-0 third edition). Eur J Cancer Prev 14:307-308, 2005 
17. Schemper $M$, Smith $T L$ : A note on quantifying follow-up in studies of failure time. Control Clin Trials 17:343-346, 1996

18. Putter H, Fiocco M, Geskus RB: Tutorial in biostatistics: Competing risks and multi-state models. Stat Med 26:2389-2430, 2007

19. Gray R: A class of K-sample tests for comparing the cumulative incidence of a competing risk. Ann Stat 16:1141-1154, 1988

20. Nederlandse Kankerregistratie. http://www cijfersoverkanker.nl/
21. de Wreede LC, Fiocco $M$, Putter $H$ : The mstate package for estimation and prediction in nonand semi-parametric multi-state and competing risks models. Comput Methods Programs Biomed 99:261-274, 2010

22. de Wreede LC, Fiocco M, Putter H: Mstate: An $\mathrm{R}$ package for the analysis of competing risks and multi-state models. J Stat Softw 38, 2011

23. Keurentjes JC, Fiocco M, Schreurs BW, et al: Revision surgery is overestimated in hip replacement. Bone Joint Res 1:258-262, 2012
24. Kumar S, Shah JP, Bryant CS, et al: Second neoplasms in survivors of endometrial cancer: Impact of radiation therapy. Gynecol Oncol 113:233239, 2009

25. Wood ME, Vogel $V$, Ng A, et al: Second malignant neoplasms: Assessment and strategies for risk reduction. J Clin Oncol 30:3734-3745, 2012

26. Renehan AG, Tyson M, Egger M, et al: Bodymass index and incidence of cancer: A systematic review and meta-analysis of prospective observational studies. Lancet 371:569-578, 2008

\section{Be the First to Hear When New Clinical Cancer Research Is Published Online}

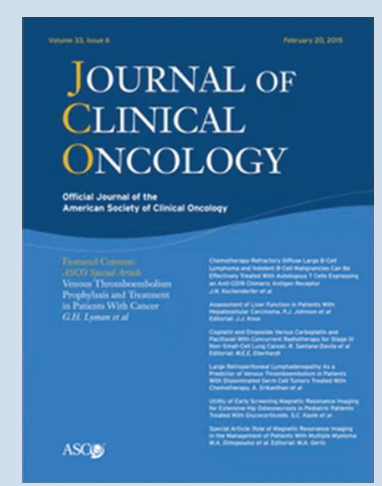

By signing up for JCO's Early Release Notification, you will be alerted and have access to new articles posted online every Monday, weeks before they appear in print. All Early Release articles are searchable and citable, and are posted on jco.org in advance of print publication. Simply go to jco.org/earlyrelease, sign in, select "Early Release Notification," and click the SUBMIT button. Stay informed-sign up today! 


\section{AUTHORS' DISCLOSURES OF POTENTIAL CONFLICTS OF INTEREST}

No Increased Risk of Second Cancer After Radiotherapy in Patients Treated for Rectal or Endometrial Cancer in the Randomized TME, PORTEC-1, and PORTEC-2 Trials

The following represents disclosure information provided by authors of this manuscript. All relationships are considered compensated. Relationships are self-held unless noted. I = Immediate Family Member, Inst = My Institution. Relationships may not relate to the subject matter of this manuscript. For more information about ASCO's conflict of interest policy, please refer to www.asco.org/rwc or jco.ascopubs.org/site/ifc.

\section{Lisette M. Wiltink}

No relationship to disclose

Remi A. Nout

No relationship to disclose

\section{Marta Fiocco}

No relationship to disclose

Elma Meershoek-Klein Kranenbarg

No relationship to disclose

Ina M. Jürgenliemk-Schulz

No relationship to disclose

\section{Jan J. Jobsen}

No relationship to disclose

\author{
Iris D. Nagtegaal \\ Research Funding: Amgen (Inst)
}

\section{Harm J.T. Rutten}

No relationship to disclose

Cornelis J.H. van de Velde

No relationship to disclose

\section{Carien L. Creutzberg}

No relationship to disclose

Corrie A.M. Marijnen

No relationship to disclose 


\section{Acknowledgment}

We thank the Dutch National Pathology Registry for contributions to data collection. 